\title{
Influence of Mg/Si Ratio on Nanocluster Formation in Al-Mg-Si Alloys with Constant Mg + Si Concentration
}

\author{
SeongNyeong Kim ${ }^{1, * 1}$, JaeHwang $\mathrm{Kim}^{1, * 2}$, Equo Kobayashi ${ }^{1}$ and Tatsuo Sato ${ }^{2}$ \\ ${ }^{1}$ Department of Metallurgy and Ceramics Science, Tokyo Institute of Technology, Tokyo 152-8552, Japan \\ ${ }^{2}$ Precision and Intelligence Laboratory, Tokyo Institute of Technology, Yokohama 226-8503, Japan
}

Two types of nanoclusters are formed during low temperature aging and play significantly important roles in age-hardening of Al-Mg-Si alloys. The formation behavior of nanoclusters markedly depends on the alloy composition. In this paper, alloy specimens with different $\mathrm{Mg} / \mathrm{Si}$ ratios in the constant $\mathrm{Mg}+\mathrm{Si}$ concentration of 1.1, 1.3 and $1.5 \mathrm{~mol} \%$ were used in order to investigate the influence of the $\mathrm{Mg} / \mathrm{Si}$ ratio on the nanocluster formation using differential scanning calorimetry (DSC), hardness and electrical resistivity measurements. Two overlapped peaks obtained by the DSC analysis are separated using the Gaussian function method and it is clarified that the volume fraction and formation kinetics of nanoclusters change with the $\mathrm{Mg} / \mathrm{Si}$ ratio even though in the constant $\mathrm{Mg}+\mathrm{Si}$ concentration. It is found that the most favorable $\mathrm{Mg} / \mathrm{Si}$ ratio for the nanocluster formation is almost 1.0 even for the different values of the $\mathrm{Mg}+\mathrm{Si}$ concentration. The influence of the $\mathrm{Mg} / \mathrm{Si}$ ratio on the nanocluster formation is discussed in terms of interactions among the solute $\mathrm{Mg}$ and $\mathrm{Si}$ atoms and vacancies in the matrix. [doi:10.2320/matertrans.L-M2014832]

(Received April 16, 2014; Accepted August 6, 2014; Published October 18, 2014)

Keywords: aluminum-magnesium-silicon alloys, nanoclusters, differential scanning calorimetry, Gaussian function method, Mg/Si ratio

\section{Introduction}

Al-Mg-Si alloys (6xxx series aluminum alloys) have been extensively used for body panels of automobiles due to their attractive properties, such as good formability which is required for forming processes and high corrosion resistance. In addition, these Al-Mg-Si alloys are well known to be hardened during a paint baking process normally performed at around $170^{\circ} \mathrm{C}$ for $1.2 \mathrm{ks}$ in the automobile manufacturing process, resulting in improving the mechanical strength due to their significant precipitation hardening. The precipitation sequence generally accepted in $\mathrm{Al}-\mathrm{Mg}-\mathrm{Si}$ alloys ${ }^{1-4)}$ is as follows:

$$
\begin{aligned}
\mathrm{SSSS} & \rightarrow \text { nanoclusters } \rightarrow \beta^{\prime \prime} \\
& \rightarrow \beta^{\prime}, \mathrm{U} 1 \text { (Type A), U2 (Type B), B' (Type C) } \\
& \rightarrow \beta, \mathrm{Si}
\end{aligned}
$$

where SSSS is the supersaturated solid solution. ${ }^{5)}$ In the manufacturing process for the body panels, the sheets of $\mathrm{Al}-\mathrm{Mg}-\mathrm{Si}$ alloys are solution heat treated at aluminum companies and normally transported to automobile companies. These sheets are exposed at room temperature (RT) during this transportation, resulting in the decrease of bakehardening $(\mathrm{BH})$ response during the paint baking process. This phenomenon is called as the "negative effect of two-step aging" and attributed to the formation of clusters during natural aging (NA). ${ }^{6}$ On the other hand, the "positive effect of two-step aging" is also reported by Chang et al. ${ }^{7)}$ Yamada et al. ${ }^{8)}$ found that the "negative effect of two-step aging" is caused by the retarded formation of the $\beta^{\prime \prime}$ phase during the $\mathrm{BH}$ treatment. In order to understand these complicated phenomena, several researches on the metastable phases have been studied in terms of their structure and chemical

\footnotetext{
${ }^{* 1}$ Graduate Student, Tokyo Institute of Technology. Corresponding author, E-mail: kim.s.aq@m.titech.ac.jp

${ }^{* 2}$ Graduate Student, Tokyo Institute of Technology. Present address: Research and Development Division, Hyundai Motor Group, 460-30, Sam-dong, Uiwang-si, Gyeonggi-do, 437-815, Korea
}

composition. ${ }^{9-13)}$ Serizawa et al. ${ }^{12)}$ proposed the characteristics of the two types of nanoclusters, i.e., Cluster (1) and Cluster (2), which play strongly important roles in the agehardening. The chemical composition of Cluster (1) formed at around RT is Si-rich at the early stage of NA. Mg atoms are gradually incorporated at the longer NA time to change composition. On the contrary, Cluster (2) approaches a certain $\mathrm{Mg} / \mathrm{Si}$ ratio with increasing its size, which is very close to that of the $\beta^{\prime \prime}-\left(\mathrm{Mg}_{5} \mathrm{Si}_{6}\right)$ phase. ${ }^{14)}$ Serizawa et al. ${ }^{14)}$ also confirmed that the "negative effect of two-step aging" is caused by the formation of Cluster (1), which cannot transform into the $\beta^{\prime \prime}$ phase due to the high thermal stability. In addition, Kim et al. ${ }^{15)}$ explained that the formation of Cluster (2) prior to the formation of Cluster (1) effectively suppresses the negative effect on the $\mathrm{BH}$ response. That is, the control of nanoclusters becomes extremely essential in terms of the formation kinetics. It is reported that the $\mathrm{Si}$ and $\mathrm{Mg}$ concentration of Al-Mg-Si alloys has a marked effect on the formation of nanoclusters. ${ }^{16,17)} \mathrm{Kim}$ et al., ${ }^{17)}$ especially, revealed that the formation of Cluster (1) is more correlated with the $\mathrm{Si}$ concentration than $\mathrm{Mg}$ concentration, whereas both the $\mathrm{Mg}$ and $\mathrm{Si}$ concentrations are important for the formation of Cluster (2). In addition, they clarified that the $\mathrm{Mg} / \mathrm{Si}$ ratio of the alloy composition is a significantly important factor in the nanocluster formation. Furthermore, in the present paper, the authors especially focus on the influence of the $\mathrm{Mg} / \mathrm{Si}$ ratio on the nanocluster formation with the constant total concentration of $\mathrm{Mg}$ and $\mathrm{Si}$ in the alloy composition.

The aims of this study are, therefore, to investigate the dependence of nanoclusters on the alloy composition and to clarify the most favorable composition for the two types of nanoclusters, Cluster (1) and Cluster (2). The activation energy for the nanocluster formation is also analyzed.

\section{Experimental Procedure}

The chemical compositions (mol\%) of the used Al-Mg-Si 
Table 1 Chemical compositions of the examined alloys (mol\%).

\begin{tabular}{|c|c|c|c|c|c|c|}
\hline \multirow{2}{*}{ Alloy } & \multicolumn{4}{|c|}{ Elements $(\mathrm{mol} \%)$} & \multirow{2}{*}{$\mathrm{Mg} / \mathrm{Si}$} & \multirow{2}{*}{$\mathrm{Mg}+\mathrm{Si}$} \\
\hline & $\mathrm{Mg}$ & $\mathrm{Si}$ & $\mathrm{Fe}$ & $\mathrm{Al}$ & & \\
\hline $9 \mathrm{M} 2 \mathrm{~S}^{* 1}$ & 0.98 & 0.20 & 0.05 & Bal. $* 2$ & 5.08 & 1.17 \\
\hline $7 \mathrm{M} 4 \mathrm{~S}$ & 0.77 & 0.37 & 0.05 & Bal. & 2.10 & 1.13 \\
\hline $5 \mathrm{M} 6 \mathrm{~S}$ & 0.58 & 0.56 & 0.04 & Bal. & 1.04 & 1.13 \\
\hline $3 \mathrm{M} 8 \mathrm{~S}$ & 0.34 & 0.74 & 0.04 & Bal. & 0.47 & 1.08 \\
\hline $9 \mathrm{M} 4 \mathrm{~S}$ & 0.98 & 0.38 & 0.05 & Bal. & 2.54 & 1.36 \\
\hline $7 \mathrm{M} 6 \mathrm{~S}$ & 0.78 & 0.56 & 0.05 & Bal. & 1.40 & 1.33 \\
\hline $5 \mathrm{M} 8 \mathrm{~S}$ & 0.52 & 0.74 & 0.04 & Bal. & 0.71 & 1.26 \\
\hline $3 \mathrm{M} 10 \mathrm{~S}$ & 0.37 & 0.90 & 0.07 & Bal. & 0.41 & 1.27 \\
\hline $9 \mathrm{M} 6 \mathrm{~S}$ & 1.01 & 0.59 & 0.05 & Bal. & 1.72 & 1.60 \\
\hline $7 \mathrm{M} 8 \mathrm{~S}$ & 0.79 & 0.76 & 0.05 & Bal. & 1.04 & 1.55 \\
\hline $8 \mathrm{M} 7 \mathrm{~S}$ & 0.87 & 0.67 & $<0.01$ & Bal. & 1.29 & 1.54 \\
\hline $5 \mathrm{M} 10 \mathrm{~S}$ & 0.62 & 0.94 & 0.07 & Bal. & 0.66 & 1.56 \\
\hline $3 \mathrm{M} 12 \mathrm{~S}$ & 0.34 & 1.10 & 0.06 & Bal. & 0.31 & 1.44 \\
\hline
\end{tabular}

${ }^{* 1}$ The letters of $\mathrm{M}$ and $\mathrm{S}$ in the first column are abbreviation of $\mathrm{Mg}$ and $\mathrm{Si}$. The number in front of $\mathrm{M}$ and $\mathrm{S}$ represent mass\% of $\mathrm{Mg}$ and $\mathrm{Si}$, respectively.

${ }^{* 2}$ Bal. denotes "balanced" and means the rest of composition of other elements except aluminum.

alloys are described in Table 1. The alloys were DC-cast, and then the alloy billets were extruded to $2 \mathrm{~mm}$ thickness at $500^{\circ} \mathrm{C}$ at Sumitomo Light Metal company (now, UACJ). The specimens contain different $\mathrm{Mg}$ (0.31 to 0.91 mass\%) and $\mathrm{Si}$ ( 0.20 to 1.14 mass \%) concentration in order to investigate the influence of the $\mathrm{Mg} / \mathrm{Si}$ ratio. The letters of $\mathrm{M}$ and $\mathrm{S}$ in the first column in Table 1 are abbreviation of $\mathrm{Mg}$ and $\mathrm{Si}$. The numbers in front of $\mathrm{M}$ and $\mathrm{S}$ represent mass $\%$ of $\mathrm{Mg}$ and $\mathrm{Si}$, respectively. Three kinds of specimens with the different $\mathrm{Mg} / \mathrm{Si}$ ratios as well as constant total solute concentration $(\mathrm{Mg}+\mathrm{Si})$ of about $1.1,1.3$ and $1.5 \mathrm{~mol} \%$ are shown in Fig. 1. The cold-rolled to the thickness of $1.3 \mathrm{~mm}$ specimens were solution heat treated at $560^{\circ} \mathrm{C}$ for $1.8 \mathrm{ks}$ in a salt bath, followed by quenching into ice-water at $0^{\circ} \mathrm{C}$ for $60 \mathrm{~s}$. These specimens are called as the as-quenched (this is abbreviated to A.Q.) alloy in this paper.

Differential scanning calorimetry (DSC), an effective technique to detect nanostructures, was carried out using a Rigaku DSC8230 instrument under a purified argon gas atmosphere after direct quenching. The specimens for the DSC measurement were made of disc shapes with $30 \mathrm{mg}$. Pure Al with $99.99 \%$ purity was used as the reference sample. After putting a specimen into the furnace, the furnace was firstly cooled down to $-50^{\circ} \mathrm{C}$ using a liquid nitrogen controller in order to keep the stable state at the low temperature, and then heated up to $500^{\circ} \mathrm{C}$ with the different heating rate of $2,5,10,15$ and $20^{\circ} \mathrm{C} / \mathrm{min}$, respectively.

After the solid solution heat treatment, alloy specimens were naturally aged at room temperature and aged at $100^{\circ} \mathrm{C}$ using an oil bath up to $2419.2 \mathrm{ks}$ ( 1 month) in order to investigate the specific formation behavior of Cluster (1) and Cluster (2), respectively. Micro-Vickers hardness was measured with a load of 200 or $300 \mathrm{~g}$ for $15 \mathrm{~s}$ using Mitsutoyo HM-102. The specimens were polished within $0.3 \mathrm{ks}$ after each fixed aging time during natural aging and aging at $100^{\circ} \mathrm{C}$. Seven indentations were measured from each

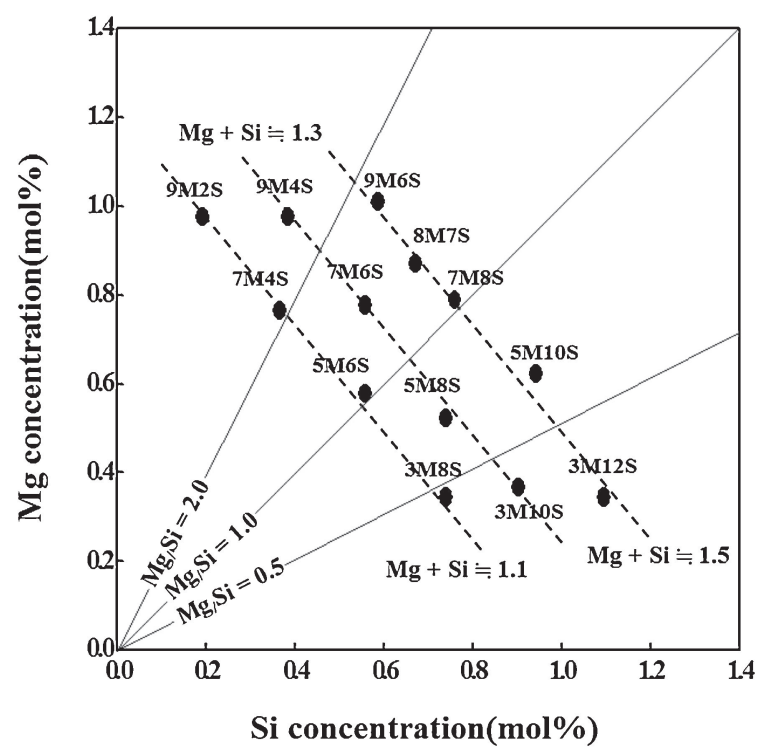

Fig. 1 Location of $\mathrm{Mg}$ and $\mathrm{Si}$ concentration (mol\%) of the used alloys. The solid lines and broken lines on the figure represent different $\mathrm{Mg} / \mathrm{Si}$ ratio and $\mathrm{Mg}+\mathrm{Si}$ concentration, respectively.

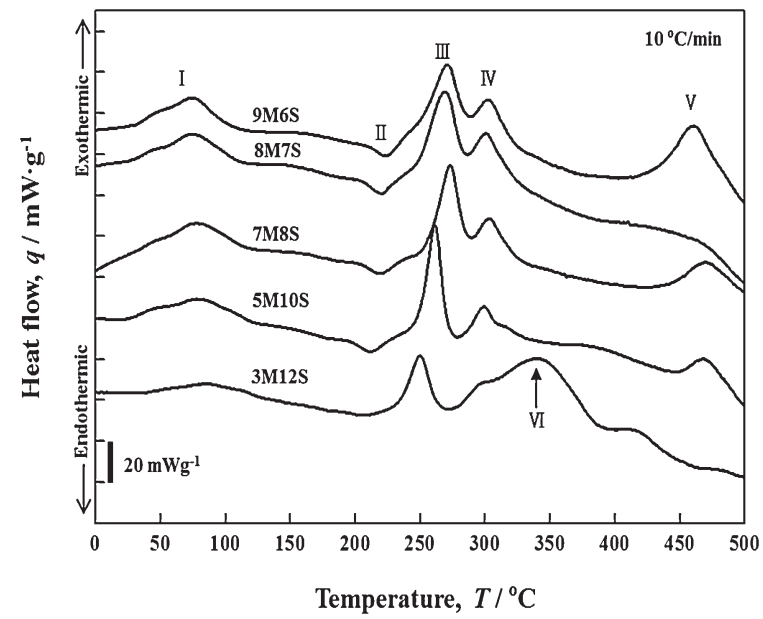

Fig. 2 Differential scanning calorimetry (DSC) curves for the as-quenched alloys with constant $\mathrm{Mg}+\mathrm{Si}$ concentration about 1.5. Peak I: formation of nanoclusters of $\mathrm{Mg}$ and $\mathrm{Si}$, Peak II: dissolution of pre-formed nanoclusters into the matrix, Peak III: precipitation of $\beta^{\prime \prime}$, Peak IV: precipitation of $\beta^{\prime}$, Peak V: precipitation of $\beta$, Peak VI: U1, U2 and B' phase (only in excess Si alloys).

specimen and cut off the maximum and minimum measured values and plotted on the averaged values. Furthermore, electrical resistivity measurements were also carried out by a four-probe method at $-196^{\circ} \mathrm{C}$ using liquid nitrogen with $120 \mathrm{~mA}$ direct current. The specimens were prepared as wires with the diameter of $1.0 \mathrm{~mm}$ and the gage length of $300 \mathrm{~mm}$.

\section{Results}

\subsection{Differential scanning calorimetry (DSC) \\ 3.1.1 DSC curves for as-quenched alloys}

Figure 2 shows DSC results of the as-quenched alloys obtained at a heating rate of $0.167 \mathrm{~K} / \mathrm{s}\left(10^{\circ} \mathrm{C} / \mathrm{min}\right)$ with a constant $\mathrm{Mg}+\mathrm{Si}$ concentration of 1.5. The DSC curves indicate the presence of four exothermic peak I (ranging from 


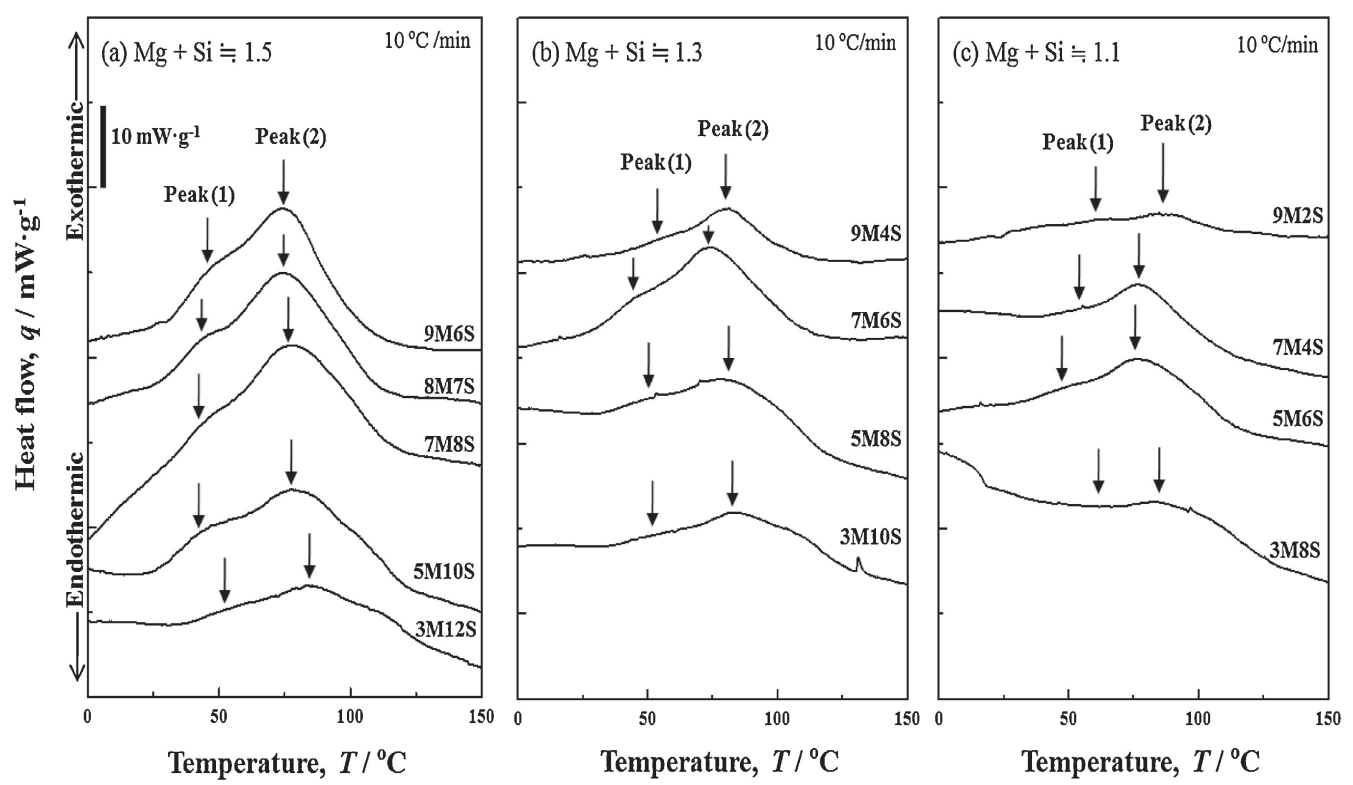

Fig. 3 DSC results showing the nanoclusters formed at low temperature in the as-quenched alloys of (a) $\mathrm{Mg}+\mathrm{Si} \fallingdotseq 1.5$, (b) $\mathrm{Mg}+\mathrm{Si} \fallingdotseq 1.3$ and (c) $\mathrm{Mg}+\mathrm{Si} \fallingdotseq 1.1$. Exothermic peaks of Peak (1) and Peak (2) are detected in all used alloys.

0 to $150^{\circ} \mathrm{C}$ ), III $\left(240\right.$ to $280^{\circ} \mathrm{C}$ ), IV (280 to $\left.300^{\circ} \mathrm{C}\right), \mathrm{V}$ (400 to $500^{\circ} \mathrm{C}$ ) and one endothermic peak II $\left(220\right.$ to $\left.240^{\circ} \mathrm{C}\right)$. Another exothermic peak designated by VI (nearby $340^{\circ} \mathrm{C}$ ) in Fig. 2 is observed only for the $3 \mathrm{M} 12 \mathrm{~S}$ alloy with excess Si. Peak I detected at a relatively low temperature range represents that the nanoclusters consisted of $\mathrm{Mg}, \mathrm{Si}$ atoms and vacancies are formed. The endothermic peak II is caused by dissolution of pre-formed nanoclusters in the $\mathrm{Al}$ matrix. Edward et al. ${ }^{1,18)}$ and Dutta et al. ${ }^{19)}$ also reported the existence of nanoclusters by means of DSC and atom probe field ion microscopy (APFIM). The exothermic reactions corresponding to peak III, IV and $\mathrm{V}$ are attributed to the precipitation of the needlelike $\beta^{\prime \prime}$, rod-like $\beta^{\prime}$ and equilibrium $\beta$ - $\left(\mathrm{Mg}_{2} \mathrm{Si}\right)$ phases. These results were also suggested by Miao et al. ${ }^{20)}$ and Gupta et al. ${ }^{21)}$ and well agree with their results. These peaks are basically similar to those in the alloys with the constant $\mathrm{Mg}+\mathrm{Si}$ concentration of 1.3 and 1.1. In particular, the peak VI, observed only in the alloy with a large amount of $\mathrm{Si}$ is considered to be the U1, U2 and $\mathrm{B}^{\prime}$ (refer to type A, B and C) phases reported by Gupta et al. ${ }^{21)}$ and Matsuda et al. ${ }^{2)}$ They also proposed that the U1, U2 and B' phases have little effect on precipitation hardening.

In this paper, the exothermic peak I corresponding to the nanocluster formation is mainly focused and discussed because nanoclusters have a significant effect on the later strengthening precipitates of $\beta^{\prime \prime}$.

The DSC curves for the nanoclusters formed between 0 to $150^{\circ} \mathrm{C}$ are enlarged and shown in Fig. 3 for the alloys with the constant $\mathrm{Mg}+\mathrm{Si}$ concentration of (a) 1.5, (b) 1.3 and (c) 1.1. Two overlapped exothermic peaks indicated by Peak (1) and Peak (2) are observed in all the examined alloys. Peak (1) and Peak (2) obtained in the present DSC curves were also detected in the low-temperature adiabatic calorimetry. ${ }^{22)}$ After that, these Peak (1) and Peak (2) are designated by two types of nanoclusters, i.e., Cluster (1) and Cluster (2), by Serizawa et al. ${ }^{11,12)}$ From these viewpoints, it is found that the Peak (1) and Peak (2) indicated in Fig. 3 are caused by the formation of Cluster (1) and Cluster (2), having different characteristics each other.

Comparing with the DSC curves in Fig. 3(a), (b) and (c), it is found that the variation of heat evolution is different depending upon the $\mathrm{Mg} / \mathrm{Si}$ ratio as well as the $\mathrm{Mg}+\mathrm{Si}$ concentration. In order to analyze these variations in more detail, two overlapped peaks are fitted to separate using the Gaussian function method. The fitting of the DSC curves to separate into two peaks using the Gaussian function method is well done as is already reported in our previous paper. ${ }^{17)}$ The formation behavior of nanoclusters is analyzed using the parameter of the peak area and peak temperature of the separated Cluster (1) and Cluster (2) peaks. In the present paper, it is regarded that the peak area directly corresponds to the volume fraction $\left(\mathrm{V}_{\mathrm{f}}\right)$ of the formed nanoclusters because this peak area is caused by the heat evolution of an exothermic reaction. It is also assumed that the peak temperature is that at which the formation of nanoclusters is most accelerated. In other words, the peak temperature shifts to lower or higher temperature depending on the formation rate of nanoclusters.

\subsubsection{Peak area and peak temperature for nanocluster formation}

Figure 4 shows peak areas of Cluster (1) and Cluster (2) in the alloys with the constant $\mathrm{Mg}+\mathrm{Si}$ concentration of $1.1,1.3$ and $1.5 \mathrm{~mol} \%$ as a function of the $\mathrm{Mg} / \mathrm{Si}$ ratio. These results are obtained based on the peaks observed in Fig. 3 in a constant heating rate of $0.167 \mathrm{~K} / \mathrm{s}\left(10^{\circ} \mathrm{C} / \mathrm{min}\right)$. It is found that the peak areas of Cluster (1) and Cluster (2) are gradually enhanced with the increasing $\mathrm{Mg}+\mathrm{Si}$ concentration. Furthermore, this result shows that the maximum value of the peak area is most enhanced when the $\mathrm{Mg} / \mathrm{Si}$ ratio is close to 1.0 for Cluster (1) and Cluster (2). That is, the volume fractions of Cluster (1) and Cluster (2) are increased with the $\mathrm{Mg} / \mathrm{Si}$ ratio closer to approximately 1.0 . It is clarified that these characteristics are markedly observed with the higher $\mathrm{Mg}+\mathrm{Si}$ concentration. 
In order to investigate the influence of the $\mathrm{Mg} / \mathrm{Si}$ ratio at different heating rates on the nanocluster formation, the DSC measurement was performed at various heating rates of 2,5 , 10,15 and $20^{\circ} \mathrm{C} / \mathrm{min}$. Figure 5 shows the results of the $7 \mathrm{M} 8 \mathrm{~S}$ alloy for the nanocluster formation with the different heating rates from 2 to $20^{\circ} \mathrm{C} / \mathrm{min}$. Other alloys with the constant $\mathrm{Mg}+\mathrm{Si}$ concentration of $1.5 \mathrm{~mol} \%$ were investigated in the same way as shown in Fig. 5. The peak area and peak temperature of Cluster (1) and Cluster (2) obtained from the DSC curves are represented as shown in Fig. 6 and Fig. 7. From the results of the peak area in Fig. 6, it is noted that the volume fraction of (a) Cluster (1) and (b) Cluster (2) is most increased in the case of the $\mathrm{Mg} / \mathrm{Si}$ ratio close to 1.0 for the different heating rate. As can be seen in the results in Fig. 7, the peak temperature has a tendency to shift to the lower temperature when the $\mathrm{Mg} / \mathrm{Si}$ ratio increases. The lowest peak temperature is obtained when the $\mathrm{Mg} / \mathrm{Si}$ is close

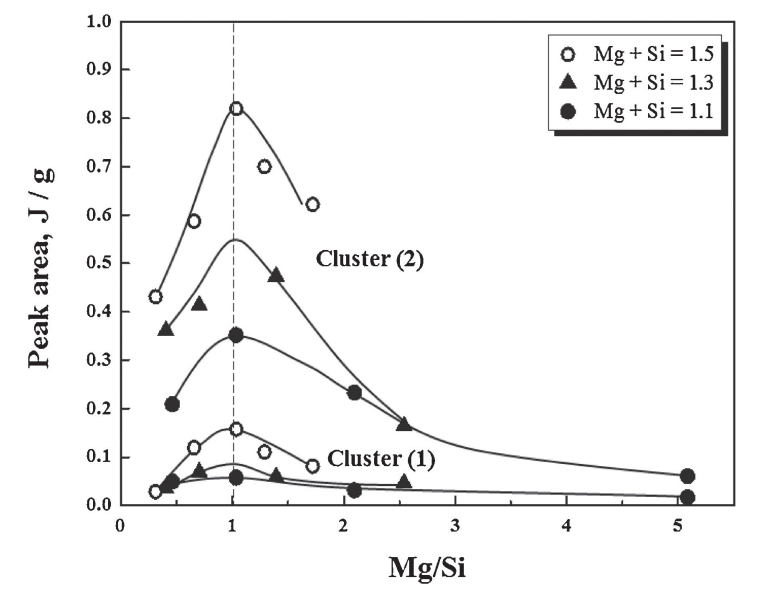

Fig. 4 Peak areas of Cluster (1) and Cluster (2) as the function of the $\mathrm{Mg}$ / Si ratio obtained by the DSC results in a heating rate of $10^{\circ} \mathrm{C} / \mathrm{min}$.

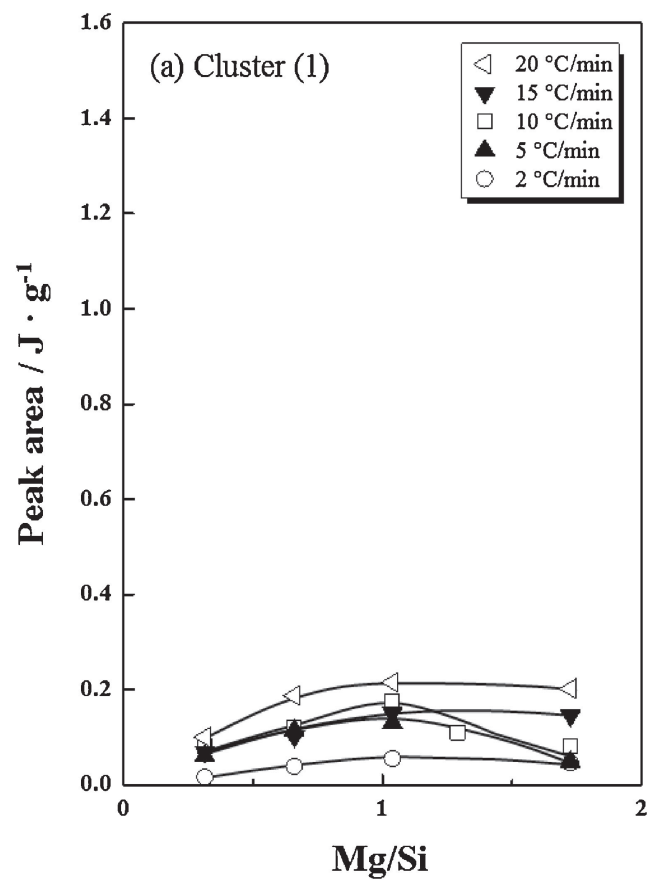

to 1.0 for Cluster (1). However, the lowest peak temperature for Cluster (2) is 1.7 of $\mathrm{Mg} / \mathrm{Si}$ ratio as seen in Fig. 7 (b). It is noted that the tendency is not changed even for the different heating rate. This shift of the peak temperature for the formation of Cluster (1) and Cluster (2) with the different heating rates is confirmed in all the examined alloys, indicating that the formation of Cluster (1) and Cluster (2) is kinetically controlled by the heating rate.

3.1.3 Formation kinetics of Cluster (1) and Cluster (2)

The formation kinetics with the different $\mathrm{Mg} / \mathrm{Si}$ ratio can be estimated by comparing the activation energy, which is the

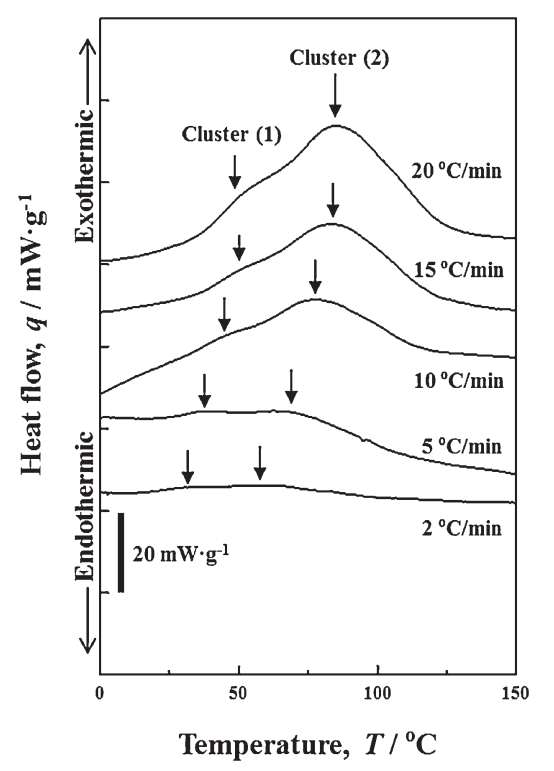

Fig. 5 DSC curves of the $7 \mathrm{M} 8 \mathrm{~S}$ alloy with the different heating rate from 2 to $20^{\circ} \mathrm{C} / \mathrm{min}$. Two detected peaks corresponding to Cluster (1) and Cluster (2) are shifted to higher temperatures with increasing heating rate as indicated by arrows.

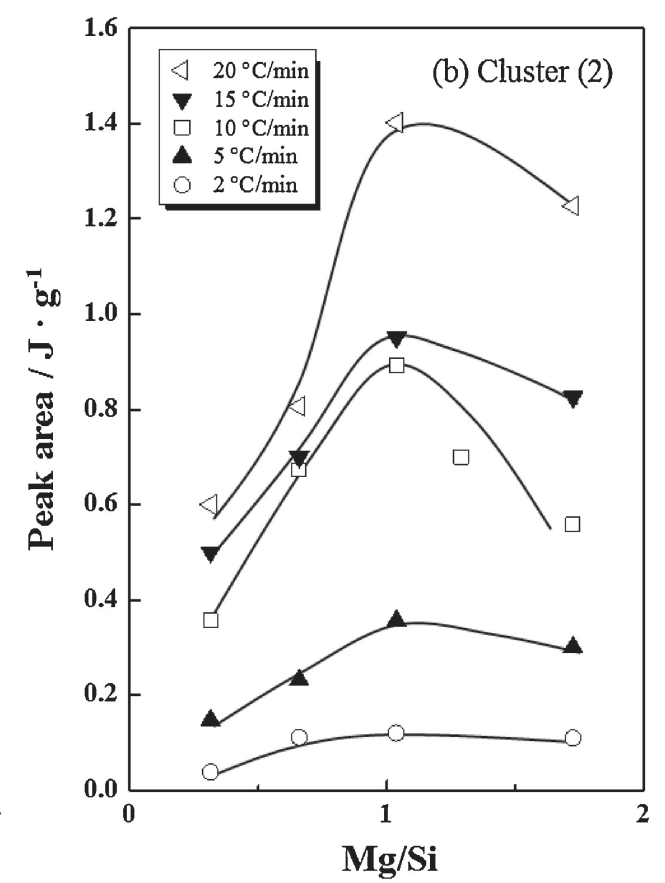

Fig. 6 Peak area vs. Mg/Si ratio of (a) Cluster (1) and (b) Cluster (2) obtained from DSC curves with various heating rates of 2, 5, 10, 15 and $20^{\circ} \mathrm{C} / \mathrm{min}(\mathrm{Mg}+\mathrm{Si} \fallingdotseq 1.5 \mathrm{~mol} \%)$. 

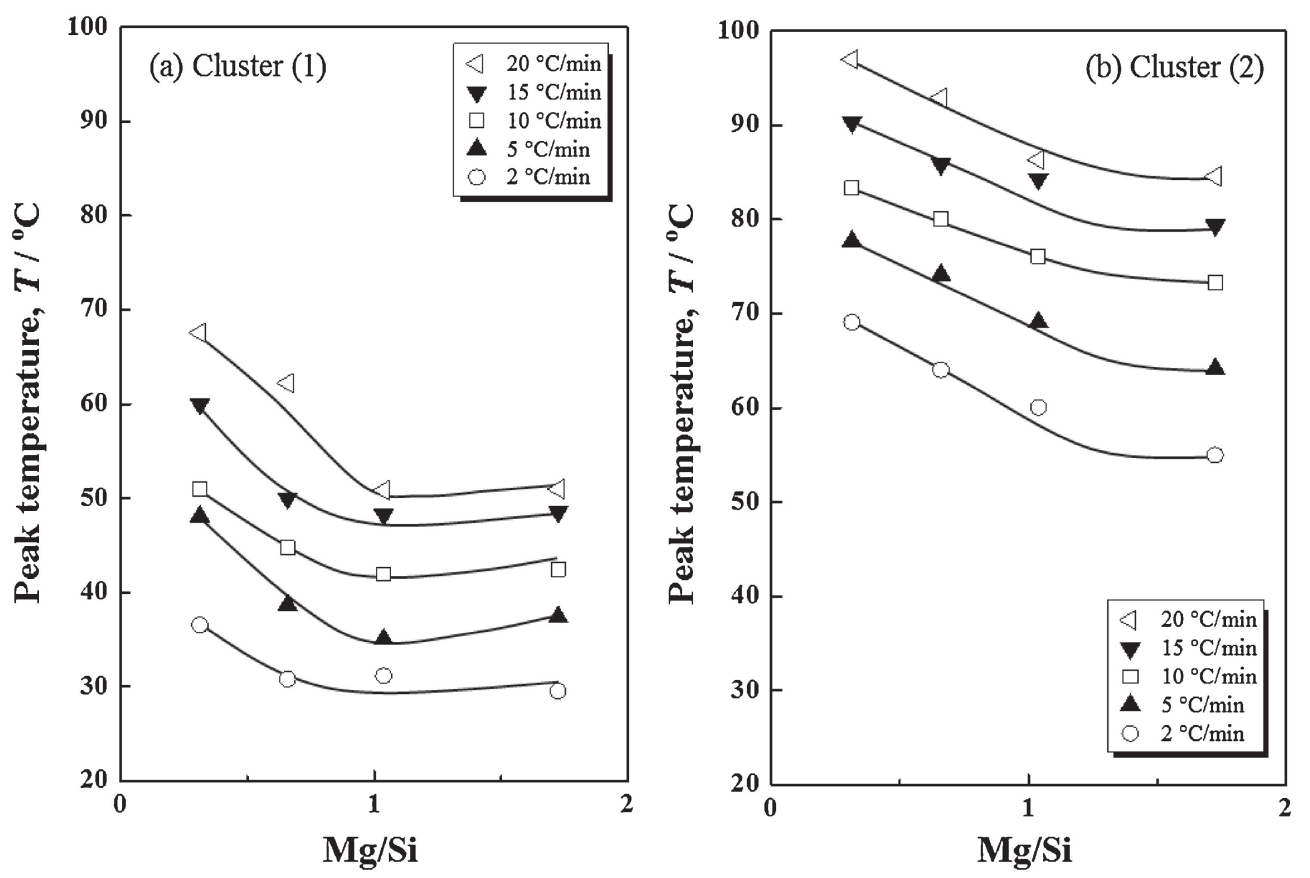

Fig. 7 Peak temperature vs. Mg/Si ratio of (a) Cluster (1) and (b) Cluster (2) obtained from DSC curves with various heating rates of 2, 5, 10,15 and $20^{\circ} \mathrm{C} / \mathrm{min}(\mathrm{Mg}+\mathrm{Si} \fallingdotseq 1.5 \mathrm{~mol} \%)$.

energy barrier required for the formation of nanoclusters. There are several methods to determine the activation energy $\left(E_{\mathrm{a}}\right)$ for the precipitation process using peak temperature of DSC results. ${ }^{23-25)}$ In this paper the generally used Kissinger method for the experimentally obtained DSC curves is applied to evaluate the activation energy for the nanocluster formation. The Kissinger equation can be written as:

$$
\ln \left(\gamma / T_{\mathrm{p}}^{2}\right)=-\left(E_{\mathrm{a}} / R\right)\left(1 / T_{\mathrm{p}}\right)+C
$$

where $\gamma, T_{\mathrm{p}}, E_{\mathrm{a}}, R$ and $C$ represent the heating rate, peak temperature, activation energy, gas constant and an constant, respectively. Figure 8(a) and (b) show the plot of $\ln \left(\gamma / T_{\mathrm{p}}{ }^{2}\right)$ as a function of $1000 / T_{\mathrm{p}}\left(\mathrm{K}^{-1}\right)$ obtained by eq. (2) for Cluster (1) and Cluster (2). Based on the slope of the plots (given by the least square fitting), the activation energies $\left(E_{1}\right.$ and $\left.E_{2}\right)$ for Cluster (1) and Cluster (2) with alloy composition were calculated and summarized in Table 2. The determined activation energies for Cluster (1) and Cluster (2) have a different value with the $\mathrm{Mg} / \mathrm{Si}$ ratio of the alloy composition. Furthermore, the much lower value for Cluster (1) formation is shown in the $7 \mathrm{M} 8 \mathrm{~S}$ alloy $(72.83 \mathrm{~kJ} / \mathrm{mol})$, whereas in the 9M6S alloy $(77.02 \mathrm{~kJ} / \mathrm{mol})$ for the Cluster (2) formation. In other words, the reaction rates of Cluster (1) and Cluster (2) are accelerated when the $\mathrm{Mg} / \mathrm{Si}$ ratio is close to 1.0 and 1.7 , respectively. These results correspond to the results of peak temperature as shown in Fig. 7. The activation energy is most decreased when the peak temperature has minimum value. The $7 \mathrm{M} 8 \mathrm{~S}$ alloy with the $\mathrm{Mg} / \mathrm{Si}$ ratio of approximately 1.0 has a largest volume fraction of nanoclusters and simultaneously low activation energy and is found to be most favorable for the formation of Cluster (1) and Cluster (2).

\subsection{Hardness and electrical resistivity changes during natural aging}

In this section, natural aging was performed to investigate the isothermal aging behavior of Cluster (1) in the alloys with
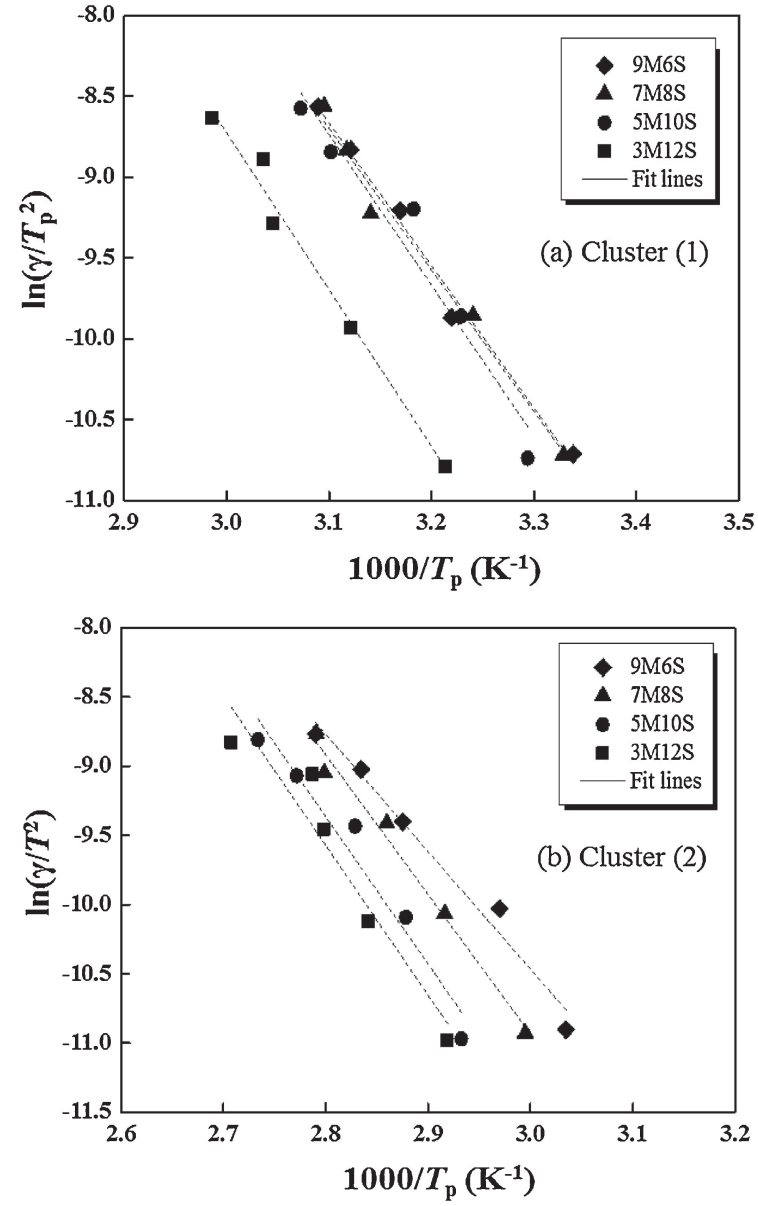

Fig. $8 \ln \left(\gamma / T_{\mathrm{p}}{ }^{2}\right)$ as a function of $1000 / T_{\mathrm{p}}$ of (a) Cluster (1) and (b) Cluster (2) showing the activation energy obtained by using the Kissinger's method $(\mathrm{Mg}+\mathrm{Si} \fallingdotseq 1.5 \mathrm{~mol} \%)$.

the constant $\mathrm{Mg}+\mathrm{Si}$ concentration of $1.5 \mathrm{~mol} \%$. Figure 9(a) and (b) show the results of electrical resistivity and hardness changes during natural aging for the different $\mathrm{Mg} / \mathrm{Si}$ ratio 
Table 2 Activation energy values for the formation of Cluster (1) and Cluster (2) determined by the Kissinger's method.

\begin{tabular}{cccc}
\hline \multirow{2}{*}{ Alloys } & \multirow{2}{*}{$\mathrm{Mg} / \mathrm{Si}$ ratio } & \multicolumn{2}{c}{ Activation energy, kJ/mol } \\
\cline { 3 - 4 } & & Cluster (1), $E_{1}$ & Cluster (2), $E_{2}$ \\
\hline 3M12S & 0.31 & 80.65 & 89.96 \\
$5 \mathrm{M} 10 \mathrm{~S}$ & 0.66 & 77.49 & 88.63 \\
$7 \mathrm{M} 8 \mathrm{~S}$ & 1.04 & 72.83 & 83.89 \\
9M6S & 1.72 & 73.25 & 77.02 \\
\hline
\end{tabular}
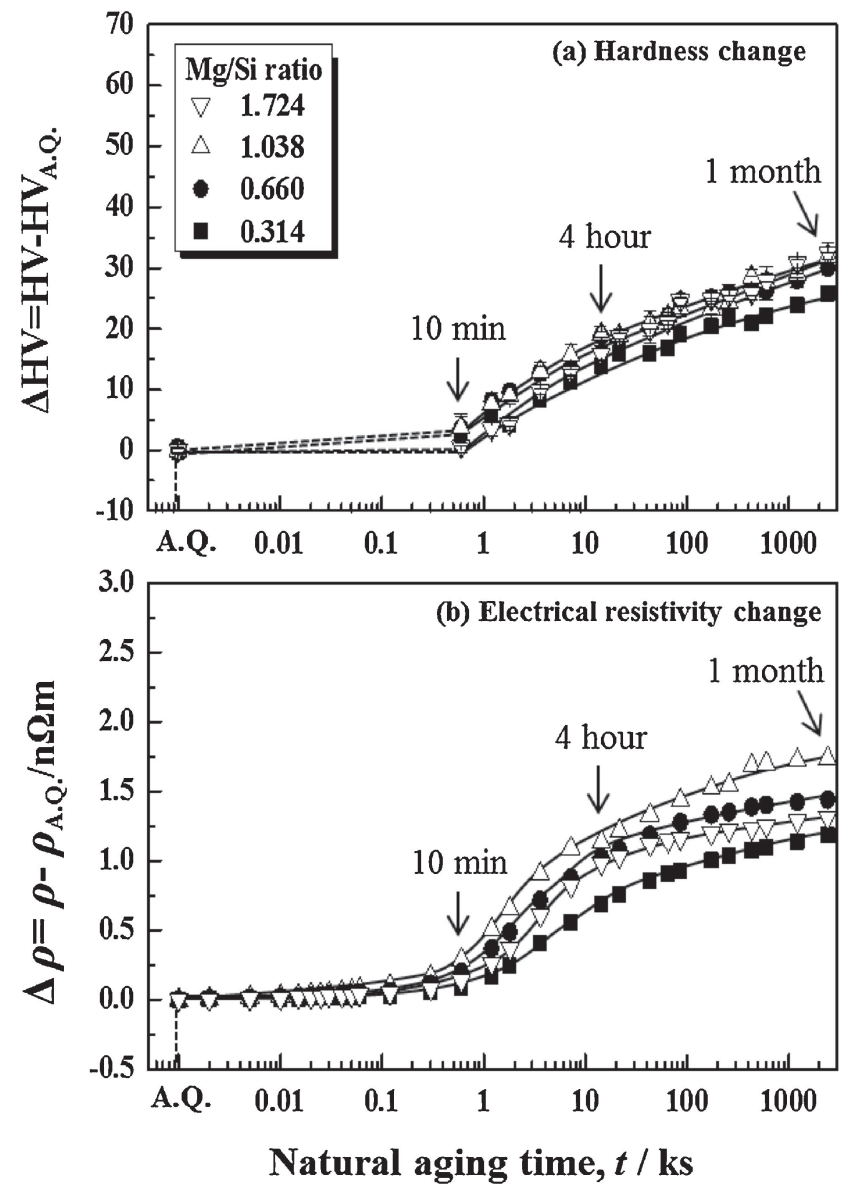

Fig. 9 (a) Hardness changes and (b) electrical resistivity changes during natural aging for various alloys with different $\mathrm{Mg} / \mathrm{Si}$ ratio. A.Q.: asquenched.

alloys. In Fig. 9(a), the hardness change $(\Delta \mathrm{HV})$ is determined by $\mathrm{HV}_{\text {measured }}-\mathrm{HV}_{\mathrm{A} . \mathrm{Q} \text {., indicating that how much }}$ Cluster (1) is formed from the supersaturated solid solution during the natural aging process. The hardness is almost unchanged at the initial stage within $0.6 \mathrm{ks}(10 \mathrm{~min})$ and fast hardening up to about $14.4 \mathrm{ks}$ (4 hour), then slow down at longer time. In addition, the influence of the $\mathrm{Mg} / \mathrm{Si}$ ratio on Cluster (1) is confirmed from the increment of hardness changes. It is found that the $7 \mathrm{M} 8 \mathrm{~S}$ alloy with the $\mathrm{Mg} / \mathrm{Si}$ ratio close to 1.0 exhibits the most increased increment of hardness. This result for the $\mathrm{Mg} / \mathrm{Si}$ ratio is also confirmed by the electrical resistivity changes during natural aging as shown in Fig. 9(b). The electrical resistivity is strongly affected by the amount of solute atoms in the $\mathrm{Al}$ matrix and the nanocluster formation. ${ }^{26)}$ As is seen in Fig. 9(b), the electrical resistivity changes are increased with the natural aging time due to the formation of Cluster (1), the solute
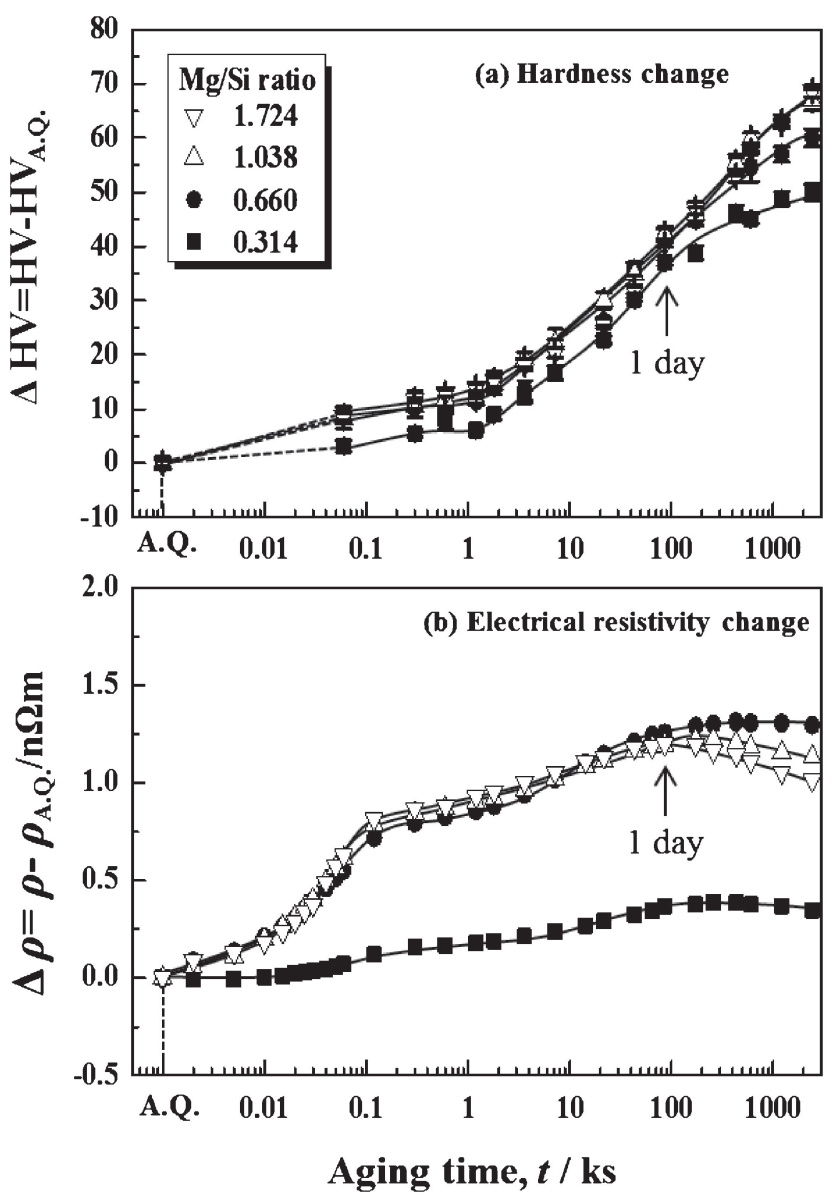

Fig. 10 (a) Hardness changes and (b) electrical resistivity changes during isothermal aging at $100^{\circ} \mathrm{C}$ for various alloys with different $\mathrm{Mg} / \mathrm{Si}$ ratio. A.Q.: as-quenched.

atoms of $\mathrm{Mg}$ and $\mathrm{Si}$ in the $\mathrm{Al}$ matrix decrease simultaneously. These results of hardness and electrical resistivity changes are in good agreement with the DSC results shown in Fig. 5 and Fig. 6.

\subsection{Hardness and electrical resistivity changes during aging at $100^{\circ} \mathrm{C}$}

In order to investigate the isothermal aging behavior of Cluster (2), aging was performed at $100^{\circ} \mathrm{C}$ for the alloys with the constant $\mathrm{Mg}+\mathrm{Si}$ concentration of $1.5 \mathrm{~mol} \%$. Figure 10(a) and (b) show the results of hardness and electrical resistivity changes during aging at $100^{\circ} \mathrm{C}$. The hardness and electrical resistivity changes are increased with the aging time due to the formation of the large amount of Cluster (2). The alloys with more than 0.66 of the $\mathrm{Mg} / \mathrm{Si}$ ratio represent almost similar behavior until about $86.4 \mathrm{ks}$ ( 1 day) and after that different behavior in both the hardness and electrical resistivity changes. Furthermore, the electrical resistivity and hardness increase more in the alloys with over 0.66 of the $\mathrm{Mg} / \mathrm{Si}$ ratio than in the $3 \mathrm{M} 12 \mathrm{~S}$ alloy $(\mathrm{Mg} / \mathrm{Si}$ ratio is 0.31 ). In other words, the formation of Cluster (2) is greatly accelerated in the alloys with more than 0.66 of the $\mathrm{Mg} / \mathrm{Si}$ ratio with increasing aging time.

\section{Discussion}

The various Al-Mg-Si alloys with the different $\mathrm{Mg} / \mathrm{Si}$ 
ratios at the constant total solute concentrations of $\mathrm{Mg}+\mathrm{Si}$ $(\mathrm{mol} \%)$ were used in order to investigate the influence of the alloy composition on the nanocluster formation. In the previous research, Kim et al. ${ }^{17)}$ reported that the $\mathrm{Si}$ and $\mathrm{Mg}$ concentration of $\mathrm{Al}-\mathrm{Mg}-\mathrm{Si}$ alloys have a marked effect on the formation of nanoclusters. The formation of Cluster (1) is more correlated with the Si concentration, whereas both of the $\mathrm{Mg}$ and $\mathrm{Si}$ concentrations affect the formation of Cluster (2). These results are closely related with the results reported by Yamada et al. ${ }^{8)}$ and Serizawa et al., ${ }^{11,12)}$ indicating that the Cluster (1) is Si-rich clusters and Cluster (2) is $\mathrm{Mg}-\mathrm{Si}$ clusters. In this paper, the alloys with the fixed constant $\mathrm{Mg}+\mathrm{Si}$ concentrations were examined in order to investigate the effect of the $\mathrm{Mg} / \mathrm{Si}$ ratio more precisely. The distributions of volume fraction of Cluster (1) and Cluster (2) with the $\mathrm{Mg}$ and $\mathrm{Si}$ concentration obtained by the DSC curves are summarized in Fig. 11, including the previous results with the 9M2S-9M12S-3M12S alloys. ${ }^{17)}$ The shaded circles are represented as a normalized value by the maximum value. The locations of the binary $\mathrm{Al}-\mathrm{Mg}$ and Al-Si alloys are also represented by arrows for understanding. From these results, it is found that the volume fraction of Cluster (1) and Cluster (2) is most enhanced when the $\mathrm{Mg} / \mathrm{Si}$ ratio is close to 1.0. In other words, a certain amount of the solute $\mathrm{Si}$ and $\mathrm{Mg}$ atoms are required for the nanocluster formation. There are a large number of structures and compositional changes in Al-Mg-Si alloys from the initial supersaturated solid solution to the equilibrium $\beta$ phase. However, the reason why the nanocluster formation is most accelerated when the value of the $\mathrm{Mg} / \mathrm{Si}$ ratio is 1.0 is not clear at the moment. The previous research has suggested that the positron lifetime related with the quenched-in excess vacancies in the binary $\mathrm{Al}-\mathrm{Mg}$ and $\mathrm{Al}-\mathrm{Si}$ alloys is rapidly decreased, comparing to the slight decrease in the Al-Mg-Si alloys. ${ }^{27)}$ These results are correlated with the fact that no exothermic clustering reaction occurs in the as-quenched Al$\mathrm{Mg}^{27,28)}$ and $\mathrm{Al}-\mathrm{Si}^{21)}$ alloys. One of the possible mechanisms is that the thermodynamically metastable state for the nanocluster formation is achieved with the matrix concentration closer to the $\mathrm{Mg} / \mathrm{Si}$ ratio of 1.0 . It is most likely that the nanocluster formation is closely correlated with the interaction energies among solute $\mathrm{Mg}$ and $\mathrm{Si}$ atoms. As the possible mechanism in the kinetics viewpoint, the activation energy, which is the combination of vacancy formation energy, migration energy and bonding energy between solute $\mathrm{Mg}$ and $\mathrm{Si}$ atoms and quenched-in excess vacancies, can be considered. It is assumed that the vacancy formation energy is less important due to the existence of quenched-in excess vacancies in the matrix. Therefore, the bonding and migration energies of the $\mathrm{Si} / \mathrm{Mg} /$ vacancy are significant factors for the nanocluster formation. The diffusion kinetics is favorable to produce nanoclusters when the $\mathrm{Mg} / \mathrm{Si}$ ratio of the matrix is close to 1.0 due to the interactions among solute atoms and vacancies. The further research is required to clarify these points in more detail, especially the relationship between the alloy composition and nanocluster composition. Furthermore, the vacancy behavior for the nanocluster formation should be also investigated. Pashley et ll $^{6)}$ firstly proposed a model taking into account the solute atom clusters, and then, Dutta and Allen ${ }^{19)}$ reported that Si-clusters are formed during low
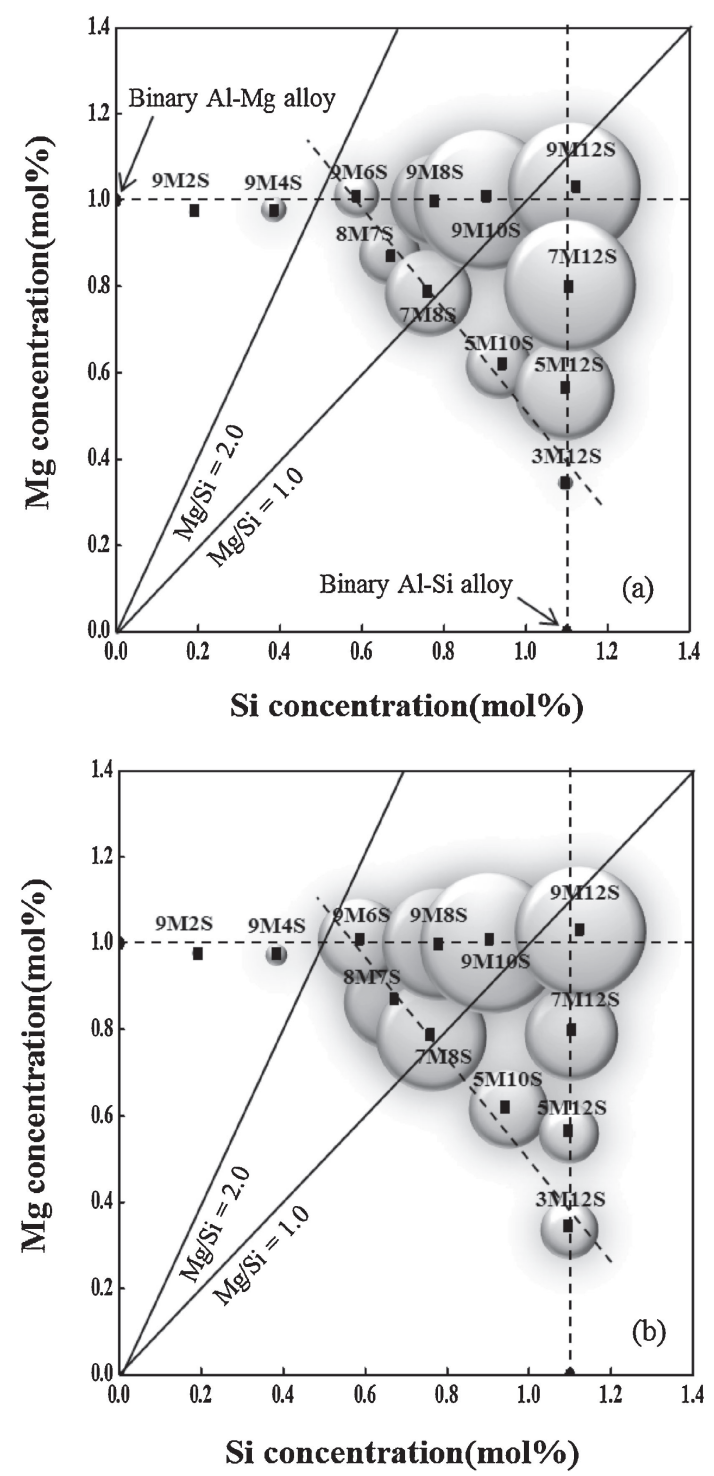

Fig. 11 Distribution of volume fraction of (a) Cluster (1) and (b) Cluster (2) represented as the function of $\mathrm{Mg}$ and $\mathrm{Si}$ concentration. Each of area was represented as a normalized value by the maximum value.

temperature aging based on the DSC analysis. In order to examine the early stage of decomposition from the supersaturated solid solution, there have been many attempts to use a more direct technique using one-dimensional atom probe field ion microscopy (APFIM) and three-dimensional atom probe (3DAP). ${ }^{10)}$ They revealed the direct evidence of the presence of Si-clusters, Mg-clusters and/or $\mathrm{Mg}-\mathrm{Si}$ co-clusters. However, the relationship between the alloy composition and cluster composition is still not clear. The alloy compositions were different in the previous researches, the difficult situation to compare. In addition, it is also complicated because of the different heat treatment temperature and time as well as the parameters of measurements. The obtained previous results by the APFIM and 3DAP are briefly summarized in Table 3, including the composition of Cluster (1) and Cluster (2), respectively. According to these summarized results, Cluster (1) has initially various $\mathrm{Mg} / \mathrm{Si}$ ratios in the alloy close to $\mathrm{Mg} / \mathrm{Si}=1.0$, whereas much more $\mathrm{Si}$-rich clusters exist than the $\mathrm{Mg}$-rich clusters in the excess $\mathrm{Si}$ alloys. $\mathrm{Mg}$ atoms are incorporated into the Si-rich clusters 
Table 3 Composition of nanoclusters, Cluster (1) and Cluster (2), with alloy composition and heat treatment.

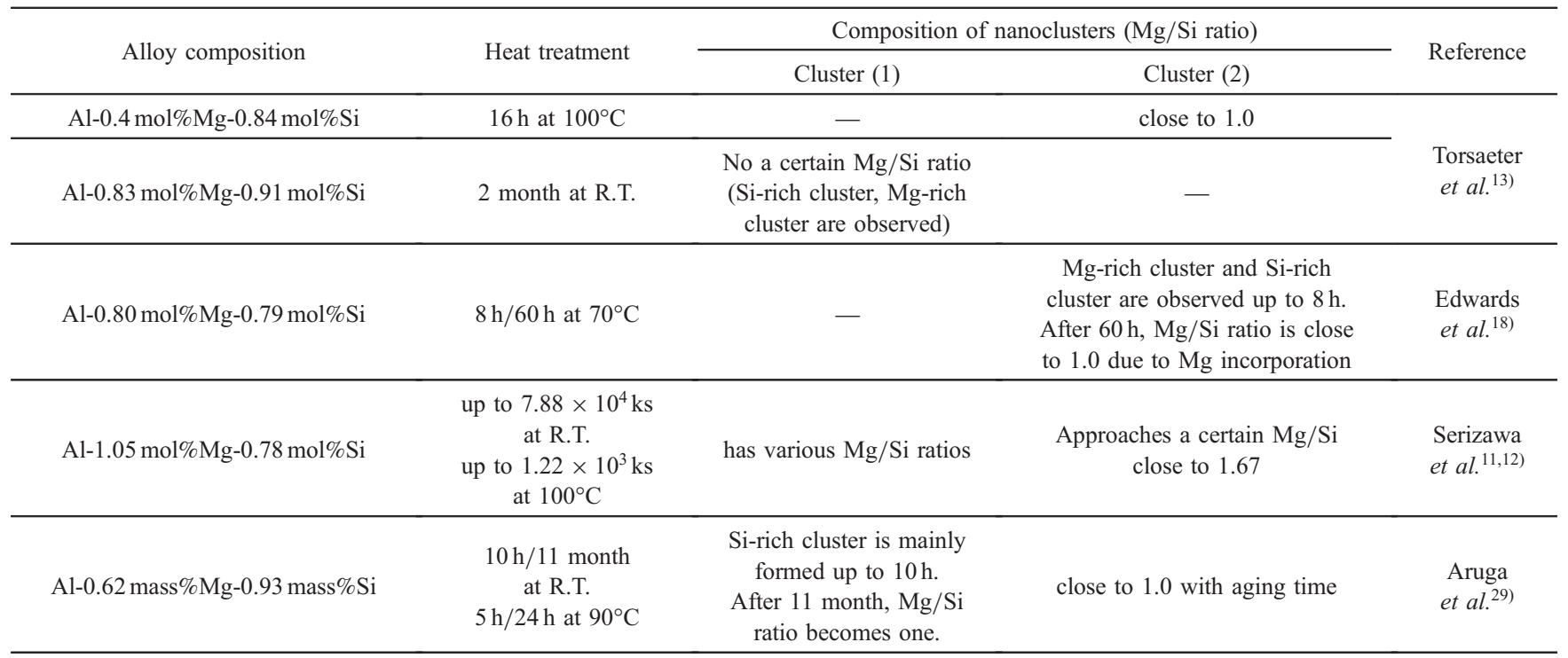

with the NA time, and then $\mathrm{Mg}$-Si co-clusters with the $\mathrm{Mg} / \mathrm{Si}$ ratio close to 1.0 are formed. In the case of Cluster (2), the $\mathrm{Mg} / \mathrm{Si}$ ratio becomes 1.0 in a short time at approximately $100^{\circ} \mathrm{C}$, different from Cluster (1) formation behavior. These results possibly explain the reason why the most favorable alloy composition is when the $\mathrm{Mg} / \mathrm{Si}$ ratio is close to 1.0 .

In order to overcome the "negative effect of two-step aging" which occurs in the manufacturing of automobile body panels, it is well understood that the transition behavior from the pre-formed nanoclusters into the strengthening $\beta^{\prime \prime}$ phase. Whether the nanoclusters transform to the $\beta^{\prime \prime}$ phase or not is determined by the several factors not only the internal composition of nanoclusters but also the atom arrangement and its thermal stability. Therefore, as a further study, the present authors make an attempt to investigate the vacancy behavior which possibly affects the internal structures of nanoclusters and the essential difference between Cluster (1) and Cluster (2).

\section{Conclusions}

The influence of the $\mathrm{Mg} / \mathrm{Si}$ ratio on the nanocluster formation with the constant total solute concentrations $\mathrm{Mg}+\mathrm{Si}$ of about $1.1,1.3$ and $1.5 \mathrm{~mol} \%$ was investigated in the present paper by means of DSC, hardness and electrical resistivity measurements. From these results conclusions are drawn as follows:

(1) Two exothermic peaks are detected using DSC measurements in the all examined alloys having the different $\mathrm{Mg} / \mathrm{Si}$ ratio with the constant $\mathrm{Mg}+\mathrm{Si}$ concentration. It is clarified that the heat evolution, the shape and position of two overlapped exothermic peaks due to the formation of Cluster (1) and Cluster (2) change with the $\mathrm{Mg} / \mathrm{Si}$ ratio change even though in the constant $\mathrm{Mg}+\mathrm{Si}$ concentration. These overlapped peaks are well separated using the Gaussian function method.

(2) The formation behavior of nanoclusters strongly depends on the $\mathrm{Mg} / \mathrm{Si}$ ratio more than the $\mathrm{Mg}+\mathrm{Si}$ concentration. The alloys with the $\mathrm{Mg} / \mathrm{Si}$ ratio of approximately 1.0 produce the largest volume fraction of nanoclusters and the lowest activation energy for the nanocluster formation, indicating that the alloy composition is the most favorable for the formation of Cluster (1) and Cluster (2). It is closely related with the interaction energies among the solute $\mathrm{Mg}$ and $\mathrm{Si}$ atoms and vacancies in the matrix.

\section{REFERENCES}

1) G. A. Edwards, K. Stiller, G. L. Dunlop and M. J. Couper: Acta Mater. 46 (1998) 3893-3904.

2) K. Matsuda, Y. Sakaguchi, Y. Miyata, Y. Uetani, T. Sato, A. Kamio and S. Ikeno: J. Mater. Sci. 35 (2000) 179-189.

3) S. J. Andersen, C. D. Marioara, A. G. Frøseth, R. Vissers and H. W. Zandbergen: Mater. Sci. Eng. A 390 (2005) 127-138.

4) C. D. Marioara, S. J. Andersen, H. W. Zandbergen and R. Holmestad: Metall. Mater. Trans. A 36 (2005) 691-702.

5) Microstructure and Properties of Aluminum, (The Japan Institute of Light Metals, 1991) p. 278.

6) D. W. Pashley, J. W. Rhodes and A. Sendorek: J. Inst. Met. 94 (1966) 41-49.

7) C. S. T. Chang, I. Wieler, N. Wanderka and J. Banhart: Ultramicroscopy 109 (2009) 585-592.

8) K. Yamada, T. Sato and A. Kamio: Mater. Sci. Forum 331 (2000) 669674.

9) W. F. Miao and D. E. Laughlin: J. Mater. Sci. Lett. 19 (2000) 201-203.

10) M. Murayama and K. Hono: Acta Mater. 47 (1999) 1537-1548.

11) A. Serizawa, S. Hirosawa and T. Sato: Mater. Sci. Forum 519-521 (2006) 245-250.

12) A. Serizawa, S. Hirosawa and T. Sato: Metall. Mater. Trans. A 39 (2008) 243-251.

13) M. Torsæter, H. S. Hasting, W. Lefebvre, C. D. Marioara, J. C. Walmsley, S. J. Andersen and R. Holmestad: J. Appl. Phys. 108 (2010) 073527.

14) A. Serizawa: Doctoral thesis, Tokyo Institute of Technology, (2008).

15) J. H. Kim, E. Kobayashi and T. Sato: Mater. Trans. 52 (2011) 906-913.

16) Y. Otsuka, A. Serizawa and T. Sato: Proc. 115th Conf. of Japan Inst. Light Metals, (2008) pp. 325-326.

17) S. N. Kim, J. H. Kim, H. Tezuka, E. Kobayashi and T. Sato: Mater. Trans. 54 (2013) 297-303. 
18) G. A. Edwards, K. Stiller and G. L. Dunlop: Appl. Surf. Sci. 76-77 (1994) 219-225.

19) I. Dutta and S. M. Allen: J. Mater. Sci. Lett. 10 (1991) 323-326.

20) W. F. Miao and D. E. Laughlin: Metall. Mater. Trans. A 31 (2000) 361371.

21) A. K. Gupta, D. J. Lloyd and S. A. Court: Mater. Sci. Eng. A 316 (2001) 11-17.

22) K. Yamada, T. Sato and A. Kamio: Mater. Sci. Forum 331-337 (2000) 669-674.

23) H. Yinnon and D. R. Uhlmann: J. Non-Cryst. Solids 54 (1983) 253 275.
24) A. Gaber, M. A. Gaffar, M. S. Mostafa and E. F. Abo Zeid: J. Alloy. Compd. 429 (2007) 167-175.

25) M. J. Starink: Thermochim. Acta 404 (2003) 163-176.

26) K. Osamura, Y. Hiraoka and Y. Murakami: Philos. Mag. 28 (1973) 809-825.

27) M. Liu, Y. Yan, Z. Liang, C. S. T. Chang and J. Banhart: Proc. 13th Conf. of ICAA13, (TMS and Wiley, 2012) pp. 1131-1137.

28) N. Afify, A. Gaber, M. S. Mostafa and Gh. Abbady: J. Alloy. Compd. 462 (2008) 80-87.

29) Y. Aruga, Y. Takaki, H. Tsuneishi, M. Kozuka and T. Sato: Proc. 124th Conf. of Japan Inst. Light Metals, (2013) pp. 143-144. 